\title{
Editorial
}

\section{Othering and Deprioritizing Older Adults' Lives: Ageist Discourses During the COVID-19 Pandemic}

\author{
Roger Andre Søraa*ab ${ }^{\star}$, Federico Manzi ${ }^{\mathrm{dd}}$, Mark W. Kharas ${ }^{\mathrm{a}}$, Antonella Marchetticd, \\ Davide Massaro cd, Giuseppe Rivade, J. Artur Serranoa
}

[a] Department of Neuromedicine and Movement Science, Faculty of Medicine and Health Sciences, NTNU Norwegian University of Science and Technology, Trondheim, Norway. [b] Department of Interdisciplinary Studies of Culture, Faculty of Humanities, NTNU Norwegian University of Science and Technology, Trondheim, Norway. [c] Research Unit on Theory of Mind, Department of Psychology, Catholic University of the Sacred Heart, Milan, Italy. [d] Humane Technology Laboratory, Catholic University of the Sacred Heart, Milan, Italy. [e] Applied Technology for NeuroPsychology Laboratory, Italian Institute for Auxology, Milan, Italy.

\begin{abstract}
The COVID-19 pandemic is showing troubling othering demographic discourses. For older adults in particular, there are concerning thematics that should be shined light on. In this editorial, we provide perspectives from three countries: Norway, Italy and the United States. We provide four topics of discussion that can be utilized to further understand othering discoures of the COVID-19 pandemic, as well as potential future disasters.
\end{abstract}

Keywords: coronavirus, COVID-19, pandemic, older adults, ageism, othering, deprioritizing

Europe's Journal of Psychology, 2020, Vol. 16(4), 532-541, https://doi.org/10.5964/ejop.v16i4.4127

Received: 2020-07-29. Accepted: 2020-09-07. Published (VoR): 2020-11-27.

*Corresponding author at: Department of Interdisciplinary Studies of Culture, Faculty of Humanities, NTNU Norwegian University of Science and Technology, Dragvoll, Edvard Bulls veg 1, 7491 Trondheim, Norway. E-mail: roger.soraa@ntnu.no

\section{Older Adults and the COVID-19 Pandemic}

Times of crises show what and who are prioritized and deprioritized. Refugee-crises are colored by racism, and homophobia hindered initial responses to HIVIAIDS. Similarly, Fraser et al. (2020), ask what society's ageist response to the COVID-19 pandemic says about us, and we argue that the initial response paints a grim picture of how we value the lives of older adults. In this editorial, we explore a discourse on the topic of "COVID-19 as an elderly disease"-which was quite prominent in the beginning of the pandemic in multiple countries (Fraser et al., 2020). The deprioritized rhetoric of "only old people die" resulted from a "public discourse [that] presented [COVID-19] as only dangerous to older adults" (Fraser et al., 2020, p. 693), which we explore as an othering of older adults' lives.

Since its modest beginning on December 31, 2019, COVID-19 has killed more than a million, infected millions, and upended the lives of billions of people in almost every country on the planet. It has also caused the 
greatest economic collapse since the Great Depression in the 1930s. Several studies found that the effects of COVID-19 symptomatology among older adults are more severe, with increased mortality (Armitage \& Nellums, 2020; Fraser et al., 2020). Lockdown policies have increased the morbidity of COVID-19 associated with affective disorders effects due to the isolation of older adults (Armitage \& Nellums, 2020; Cavalera et al., 2017). Residents of long-term care facilities are also especially vulnerable (Comas-Herrera et al., 2020). This considerable difference in the mortality rate would create an expectation that special attention and care should be focused on this age group (Comas-Herrera et al., 2020). However, this did not seem to be the case, and public mentions were made in the opposite direction of deprioritizing care for older adults as described in this article.

This can be understood as an implicit geronticide of the world's older adults population. Brogden (2001, p. 12) describes how geronticide- - "the killing of the elderly"- can be understood not in the sensational evil act of slaughtering, but in the silent societal infrastructures that "determine that older people should lose their fundamental right to life" by rationing health resources in favor of other age cohorts. There are troubling cases-most notably in Italy (Vergano et al., 2020) and Spain (de Frutos \& Moynihan, 2020; Sills \& Lombrana, 2020)_of doctors having to choose who lives and who dies based on the availability of ventilators and other medical equipment.

\section{The Effect of COVID-19 on Psychological Well-Being of Older}

\section{Adults}

The psychological effects of COVID-19 on the elderly population have been widely recognized in recent months (Armitage \& Nellums, 2020; Nobles et al., 2020; Troutman-Jordan \& Kazemi, 2020), as well as the importance of analyzing how different countries managed the first months of the pandemic to avoid even worse consequences for older adults (Chaurasia et al., 2020; Monahan et al., 2020). As matter of fact, COVID-19 mainly affects the most physically frail people and those with previous diseases, so older adults are the demographic most at risk (Liu et al., 2020; Shahid et al., 2020). Furthermore, in the early stages of the pandemic, both official communications from several countries first affected by the infection and the media repeatedly stressed that the virus was primarily dangerous for the older adults (Ayalon et al., 2020; Jimenez-Sotomayor et al., 2020; Monahan et al., 2020; Rahman \& Jahan, 2020).

In the light of this global situation, several studies have addressed the psychological well-being of older adults. In a study conducted in China, data were collected on 1,556 subjects aged between 60 and 80 years (Meng et al., 2020). The results showed that older people displayed symptoms of depression and anxiety during the pandemic. These data are supported by another study by Qiu and colleagues (2020), also carried out in China on 52,730 subjects, which showed that individuals over 60 were more inclined to symptoms including anxiety, depression, specific phobia and compulsive behaviour. More specifically, the high levels of stress experienced by the older adults in this study could be due to evidence that the highest mortality of the virus occurred among older adults (Qiu et al., 2020).

These two studies highlight how older people are susceptible to greater psychological stress, although the study by Qiu and colleagues (2020) also showed that other groups, such as young people and migrant workers, are also particularly vulnerable to psychological stress. A study by López and colleagues (2020) on a Spanish 
sample of 878 subjects showed that people between $60-70$ and 71-80 did not significant differ with respect to the negative effects of COVID-19 on psychological well-being. Although no significant age differences were found, other variables, such as the loss of a loved one during the pandemic, had negative consequences on the psychological well-being of older adults. Finally, another study by Kivi and colleagues (2020) on 1,071 Swedish older adults between 65 and 71 years highlighted how subjective experiences had a significant impact on the psychological well-being of older adults during the pandemic. More specifically, those who worried more about the health status and financial consequences of the pandemic reported lower psychological well-being. However, it is important to point out that these data relate to the first weeks of the pandemic, so further studies need to be conducted to confirm the findings.

These early studies, on the one hand, showed that the psychological well-being of older adults was generally under considerable stress and, on the other, highlighted the importance of considering individual differences to understand the negative psychological effects of the pandemic (Inghilleri et al, 2015; Marchetti et al., 2020).

\section{The "Othering" of Older Adults}

The othering process represents a strongly interdisciplinary concept that intersects different disciplines including psychology, sociology, anthropology, philosophy to name but a few. In this paragraph, despite the complex articulation of this concept, two fundamental perspectives will be presented that highlight two aspects of this process: psychoanalysis, which states that the process of the othering is fundamental for the constitution of the Self, and sociology, where this process is susceptible to historical-cultural changes and often leads to increased inequalities towards different members of society.

From a psychoanalytic perspective, one of the fundamental processes for the construction of the Self is the gradual recognition of the external object, the Other, as an independent subject (Kohut, 1971). Moreover, psychoanalytic theories have shown that We project the undesirable or repressed contents of our unconscious onto the Other (Freud, 1922). This process of creating the Other is, therefore, constitutive of our development (Stern, 1983) and constantly active throughout our lives. This individual process is also found in the social dynamics of the Other (de Beauvoir, 2011) which are subject to historical-cultural changes. Sociology refers to the othering as a negative process that leads to discrimination and exclusion of individuals on the basis of their belonging to marginalized groups of society (Boréus, 2006; Riggins, 1997). This process is even more evident when society is facing moments of severe structural crisis, as is happening during the COVID-19 pandemic.

Therefore, while for psychoanalysis the othering is conceptualized as a fundamental process for the creation of the Self and, consequently, for the individual to be in tune with society, for sociology it represents a process of separation and exclusion of the Other from the society (Hall, 1997). More specifically, the Other "means transforming the Other into another, thus creating a boundary between different and similar, insider and outsider. The emotional and cognitive mechanisms leading to the Other are articulated linguistically and co-constructed interactively but also on a social and supranational level" (Dervin, 2015, p. 2)

Since the 1970s, the process of othering has also been recognized and studied with respect to age, particularly towards the elderly: this process has been defined as ageism (Butler, 1969; Nelson, 2002). The World Health Organization (WHO) has defined ageism as "the stereotype, prejudice and discrimination against people based on their age" (WHO, n.d.). Generally, othering—including ageism—has negative effects on both individuals 
and groups, e.g. through social exclusion and stigmatization. However, in a psychoanalytic discourse, normal development involves construction of the Other, therefore the othering process is common, especially when the Self's equilibrium is jeopardized. A pandemic certainly jeopardizes society's equilibrium; therefore, preventing othering on a societal level requires intentional societal action. The ease with which othering occurs is demonstrated by initial public communications regarding the mortality of COVID-19 and, consequently, the rhetoric adopted by the media: a strong tendency to separate Us, the younger and less at-risk people, and the Other, the older people in risk groups. This process seems to have exacerbated stereotypes towards older people, increasing their exclusion from public discourse early on and leading to negative consequences in protecting their physical and mental health (Cesari \& Proietti, 2020).

\section{"Othering" Discourse in Norway, Italy and the USA}

For the present analysis of the process of social othering to which older adults have been subjected, three countries were considered: Italy, Norway and the USA. The reason for the inclusion of these countries is a common aspect of the first COVID-19 emergency management: the first official communications were oriented to support the process of othering towards older adults and the more fragile segments of the population, promoting the idea that the virus would only affect older adults and people with previous pathologies-however, as the pandemic progressed, the countries chose widely different approaches to deal with the resulting situations. As will be shown below, the analysis of the official documents and the first news provided by the mass media will show that the process of social othering of older adults is independent from the specific demographic composition of the population in terms of aging. The following examples were chosen based on searches and media examples that emerged during the first couple months after the pandemic outbreak.

In the United States, the Federal Government has issued reminders of the illegality of explicit age-based discrimination in treatment (Fink, 2020). Ethicists have argued for (Emanuel et al., 2020) and against (Bagenstos, 2020) using age as a factor in rationing care. News articles stress the horror of explicitly using age, while recognizing that rationing plans will, implicitly, often result in treatment disparities based on age; there seems to be acceptance if unease (Fink, 2020). However, substantial media coverage of a potentially COVID-related inflammatory condition among young children is noticeable, given that the number of cases-several hundred-is small in the context of the pandemic as a whole (Belluck, 2020). Therefore, while explicit ageism is shunned, implicit bias is alive and well.

Italy's early official communications, as late as February 20, implicitly highlighted the occurrence of COVID-19 only in vulnerable populations (older adults and sick; Italian Ministry of Health, 2020), leading to the Italian media propagating the misleading rhetoric that "only older adults, not the young" are affected and contributing to young people rejecting social distancing restrictions. Furthermore, the spread of the virus among older adults has worsened due to a poor application of preventive measures in nursing homes, also associated with an initial shortage in these contexts of masks and gloves, which has also led to an increase in the infected among employees. Because of this, the media has written about the "massacre of the elderly" in nursing homes (di Fio et al., 2020). This shows some outrage over the de-prioritization of older adults, but an early lack of urgency likely contributed to these situations.

Norway's border closed down on March 16, when the most restrictive societal regulations since WWII were put in place. But the public discourse was largely around protecting older adults. The Prime Minister specifically 
recommended that grandparents not undertake childcare while schools were closed (Ripegutu, 2020). There was also a temporary ban on going to cabins, which are often owned by young, healthy people but are located in rural, poorer, and older communities with fewer healthcare resources. This was only put in place to respond to widespread behavior that put older adults at risk, showing that even when government policy tries to foreground older adults' concerns, societal practice often works against it.

\section{Four Points of Discussion for Ageism and Othering in Pandemics}

Based on these observations we offer the following four provocative questions for stimulating a discussion on what we see as othering of older adults during pandemics—which can be used to further implement more inclusive and just strategies for dealing with pandemics. Being aware of ageist bias in times of crisis can help prepare, mitigate and take action to make societies more inclusive, responsible and just.

\section{What is Risked by Portraying COVID-19 as an "Elderly-Disease"?}

Fraser et al. (2020) have pointed out how this is not a disease of older adults, and that "the effects will be felt by everyone. We all must do our part to curtail its spread" (p. 3). Younger people may chafe at the loss of autonomy or economic pain caused by social distancing, even using \#BoomerRemover on social media, while older adults feel forgotten and devalued. How will this affect generational divides, going in both directions?

\section{What Can Intersections of Social Groups and Empathy Teach Us?}

Social determinants of health, especially smoking, homelessness, race, ethnicity, and poverty, play a large role in the morbidity of COVID-19 (Abrams \& Szefler, 2020). Addressing these is politically fraught even outside of COVID-19. This time the pandemic especially hit older adults, but would societies have reacted differently if children were the main victims? Articles like Belluck's (2020) suggest very differently. As Fraser et al. (2020) paradoxically point out: "The death of a young adult merits a life story, while the death of an older adult is too often merely a statistic" (p. 693). The next pandemic might hit different societal groups, which is why it is crucial to learn from othering and ageism, to avoid other future discriminatory discourses.

\section{Who Decides, Legislates and Governs Who Should Have Access to Healthcare and Resources?}

"More than 140 world leaders, experts and elders have made an unprecedented call for guarantees that COVID-19 vaccines, diagnostics, tests and treatments will be provided free of charge to everyone, everywhere" (UNAIDS, 2020). The implementation of such laudable aspirations depends on the actions of the businesses, governments, and hospitals relating to the overall infrastructure of care. It is possible, perhaps probable, that both macro and micro socioeconomic conditions that are emblematic of othering will determine access to care. Widespread recognition and intentional political action will be needed to counteract such disparities. 


\section{How is Governance, Personal Freedom, and Health Balanced in Times of Crises?}

One common, if anecdotal, theme is that government communications can contribute to othering discourses and that such discourses exist even when the government works to combat it. These discourses can make it politically or socially difficult to undertake mitigation efforts that curtail personal freedoms and can, when they are implemented, lead to societal backlash against the populations protected by these efforts. Given these realities, how can the government work with other societal influencers to both encourage behavior necessary for public health while not contributing to ageism or other othering?

\section{Summary}

The COVID-19 public discourse, particularly in early stages, led to an othering and deprioritizing of older adults, whose lives were portrayed as less worthy than "the rest" of the population. We problematize this discourse by looking at experiences from the United States, Italy, and Norway. Better inclusion of older adults into the fabrics of societies can make for a more just, caring, and robust world—pre, during and post pandemics. We thus provided four inquiries of ageism and othering that societal stakeholders should consider to avoid othering vulnerable societal groups in future pandemics and disasters.

\section{References}

Abrams, E. M., \& Szefler, S. J. (2020). COVID-19 and the impact of social determinants of health. The Lancet: Respiratory Medicine, 8(7), 659-661. https://doi.org/10.1016/S2213-2600(20)30234-4

Armitage, R., \& Nellums, L. B. (2020). COVID-19 and the consequences of isolating the elderly. The Lancet: Public Health, 5(5), Article e256. https://doi.org/10.1016/S2468-2667(20)30061-X

Ayalon, L., Chasteen, A., Diehl, M., Levy, B. R., Neupert, S. D., Rothermund, K., . . Wahl, H.-W. (2020). Aging in times of the COVID-19 pandemic: Avoiding ageism and fostering intergenerational solidarity. The Journals of Gerontology. Advance online publication. https://doi.org/10.1093/geronb/gbaa051

Bagenstos, S. R. (2020). Who gets the ventilator? Disability discrimination in COVID-19 medical-rationing protocols. The Yale Law Journal, 130, 1-25. Retrieved from https://www.yalelawjournal.org/forum/who-gets-the-ventilator

Belluck, P. (2020, May 13). New inflammatory condition in children probably linked to coronavirus, study finds. Retrieved from https://www.nytimes.com/2020/05/13/health/coronavirus-children-kawasaki-pmis.html

Boréus, K. (2006). Discursive discrimination: A typology. European Journal of Social Theory, 9(3), 405-424. https://doi.org/10.1177/1368431006065721

Brogden, M. (2001). Geronticide: Killing the elderly. London, United Kingdom: Jessica Kingsley Publishers.

Butler, R. N. (1969). Age-ism: Another form of bigotry. The Gerontologist, 9(4_Part_1), 243-246. https://doi.org/10.1093/geront/9.4_Part_1.243 
Cavalera, C., Pepe, A., Zurloni, V., Diana, B., \& Realdon, O. (2017). A short version of the State Shame and Guilt Scale (SSGS-8). TPM: Testing, Psychometrics, Methodology in Applied Psychology, 24(1), 99-106. https://doi.org/10.4473/TPM24.1.6

Cesari, M., \& Proietti, M. (2020). COVID-19 in Italy: Ageism and decision making in a pandemic. Journal of the American Medical Directors Association, 21(5), 576-577. https://doi.org/10.1016/j.jamda.2020.03.025

Chaurasia, N., Singh, A., \& Singh, I. L. (2020). COVID-19: Psychological impact of a pandemic disease. Research Reports. Advance online publication. Retrieved from http://companyofscientists.com/index.php/rr/article/view/176

Comas-Herrera, A., Zalakaín, J., Litwin, C., Hsu, A. T., Lemmon, E., Henderson, D., \& Fernández, J.-L. (2020). Mortality associated with COVID-19 outbreaks in care homes: Early international evidence. Retrieved from https://ltccovid.org/wp-content/uploads/2020/06/Mortality-associated-with-COVID-among-people-who-use-long-termcare-26-June.pdf

de Beauvoir, S. (2011). The second sex (C. Borde \& S. Malovany-Chevallier, Trans.). New York, NY, USA: Vintage International. (Original book published in 1949)

de Frutos, A. M., \& Moynihan, R. (2020, April 15). A nurse in Madrid says lack of supplies is leaving Spanish healthcare workers to make difficult choices about who to save and who to let die. Retrieved from https://www.businessinsider.com/coronavirus-lockdown-pandemic-healthcare-medical-staff-ppe-equipment-doctorsspain-2020-4?r=US\&IR=T

Dervin, F. (2015). Discourses of othering. In K. Tracy, T. Sandel, \& C. Ilie (Eds.), The international encyclopedia of language and social interaction (pp. 1-9). Hoboken, NJ, USA: Wiley. https://doi.org/10.1002/9781118611463.wbielsi027

di Fio, D. G., Baldessarro, G., Bocci, M., Bulfon, F., Sazzi, Z., di Raimondo, R., \& Gallione, A. (2020, May 27). La strage silenziosa delle rsa. Retrieved from https://rep.repubblica.it/pwa/longform/2020/05/27/news/rsa_morti_coronavirus_trivulzio-257664697/

Emanuel, E. J., Persad, G., Upshur, R., Thome, B., Parker, M., Glickman, A., . . Phillips, J. P. (2020). Fair allocation of scarce medical resources in the time of COVID-19. The New England Journal of Medicine, 382(21), $2049-2055$. https://doi.org/10.1056/NEJMsb2005114

Fink, S. (2020, March 29). U.S. Civil Rights Office rejects rationing medical care based on disability, age. Retrieved from https://www.nytimes.com/2020/03/28/us/coronavirus-disabilities-rationing-ventilators-triage.html

Fraser, S., Lagacé, M., Bongué, B., Ndeye, N., Guyot, J., Bechard, L., . . Tougas, F. (2020). Ageism and COVID-19: What does our society's response say about us? Age and Ageing, 49(5), 692-695. https://doi.org/10.1093/ageing/afaa097

Freud, S. (1922). Beyond the pleasure principle (C. M. J. Hubback, Trans.). London, United Kingdom: International Psychoanalytical Press. https://doi.org/https://doi.org/10.1037/11189-000

Hall, S. (1997). The spectacle of the "other". In S. Hall (Ed.), Representation: Cultural representations and signifying practices. New York, NY, USA: SAGE Publications.

Inghilleri, S., Riva, G., \& Riva, E. (Eds.). (2015). Introduction: Positive change in global world: Creative individuals and complex societies. In Enabling positive change: Flow and complexity in daily experience (pp. 1-5). Berlin, Germany: De Gruyter. 
Italian Ministry of Health. (2020). \#coronavirus. Il nuovo coronavirus colpisce solo le persone anziane o anche i più giovani? Retrieved from http://www.salute.gov.it/portale/news/p3_2_7_0_1.jsp?lingua=italiano\&menu=multimedia\&p=video\&id=2024

Jimenez-Sotomayor, M. R., Gomez-Moreno, C., \& Soto-Perez-de-Celis, E. (2020). Coronavirus, ageism, and Twitter: An evaluation of tweets about older adults and COVID-19. Journal of the American Geriatrics Society, 68(8), 1661-1665. https://doi.org/10.1111/jgs.16508

Kivi, M., Hansson, I., \& Bjälkebring, P. (2020). Up and about: Older adults' well-being during the COVID-19 pandemic in a Swedish longitudinal study. The Journals of Gerontology. Advance online publication. https://doi.org/10.1093/geronb/gbaa084

Kohut, H. (1971). The analysis of the self: A systematic approach to the psychoanalytic treatment of narcissistic personality disorders. New York, NY, USA: International Universities Press.

Liu, K., Chen, Y., Lin, R., \& Han, K. (2020). Clinical features of COVID-19 in elderly patients: A comparison with young and middle-aged patients. The Journal of Infection, 80(6), e14-e18. https://doi.org/10.1016/j.jinf.2020.03.005

López, J., Perez-Rojo, G., Noriega, C., Carretero, I., Velasco, C., Martinez-Huertas, J. A., . . Galarraga, L. (2020). Psychological well-being among older adults during the COVID-19 outbreak: A comparative study of the young-old and the old-old adults. International Psychogeriatrics. Advance online publication.

https://doi.org/10.1017/S1041610220000964

Marchetti, A., Di Dio, C., Massaro, D., \& Manzi, F. (2020). The psychosocial fuzziness of fear in the coronavirus (COVID-19) era and the role of robots. Frontiers in Psychology, 11, Article 2245. https://doi.org/10.3389/fpsyg.2020.02245

Meng, H., Xu, Y., Dai, J., Zhang, Y., Liu, B., \& Yang, H. (2020). Analyze the psychological impact of COVID-19 among the elderly population in China and make corresponding suggestions. Psychiatry Research, 289, Article 112983. https://doi.org/10.1016/j.psychres.2020.112983

Monahan, C., Macdonald, J., Lytle, A., Apriceno, M., \& Levy, S. R. (2020). COVID-19 and ageism: How positive and negative responses impact older adults and society. The American Psychologist. Advance online publication. https://doi.org/10.1037/amp0000699

Nelson, T. D. (Ed.). (2002). Ageism: Stereotyping and prejudice against older persons. Cambridge, MA, USA: MIT Press.

Nobles, J., Martin, F., Dawson, S., Moran, P., \& Savovic, J. (2020). The potential impact of COVID-19 on mental health outcomes and the implications for service solutions. Retrieved form https://arc-w.nihr.ac.uk/Wordpress/wp-content/uploads/2020/04/COVID-19-Rapid-Review-COVID-and-Mental-HealthFINAL.pdf

Qiu, J., Shen, B., Zhao, M., Wang, Z., Xie, B., \& Xu, Y. (2020). A nationwide survey of psychological distress among Chinese people in the COVID-19 epidemic: Implications and policy recommendations. General Psychiatry, 33(2), Article e100213. https://doi.org/10.1136/gpsych-2020-100213

Rahman, A., \& Jahan, Y. (2020). Defining a 'risk group' and ageism in the era of COVID-19. Journal of Loss and Trauma, 25(8), 631-634. https://doi.org/10.1080/15325024.2020.1757993 
Riggins, S. H. (Ed.). (1997). The language of politics of exclusion: Others in discourse. New York, NY, USA: SAGE Publications.

Ripegutu, H. (2020, March 20). Erna Solberg kommer med viktig advarsel om barnepass. Retrieved from https://www.nettavisen.no/nyheter/erna-solberg-kommer-med-viktig-advarsel-om-barnepass/3423936153.html? fbclid=IwAR0ogceq74cZYYHYwknqAjiGInm4TkrLQ-VvpGogiTIZfO2csMd2a8uH2Po

Shahid, Z., Kalayanamitra, R., McClafferty, B., Kepko, D., Ramgobin, D., Patel, R., . . Jain, R. (2020). COVID-19 and older adults: What we know. Journal of the American Geriatrics Society, 68(5), 926-929. https://doi.org/10.1111/jgs.16472

Sills, B., \& Lombrana, L. M. (2020, March 25). Spanish doctors are forced to choose who to let die. Retrieved from https://www.bloomberg.com/news/articles/2020-03-25/spanish-doctors-forced-to-choose-who-to-let-die-from-coronavirus

Stern, H. H. (1983). Fundamental concepts of language teaching. Oxford, United Kingdom: Oxford University Press.

Troutman-Jordan, M., \& Kazemi, D. M. (2020). COVID-19's impact on the mental health of older adults: Increase in isolation, depression, and suicide risk. An urgent call for action. Public Health Nursing, 37(5), 637-638. https://doi.org/10.1111/phn.12774

UNAIDS. (2020, May 14). World leaders unite in call for a people's vaccine against COVID-19. Retrieved from https://www.unaids.org/en/resources/presscentre/pressreleaseandstatementarchive/2020/may/20200514_covid19vaccine

Vergano, M., Bertolini, G., Giannini, A., Gristina, G., Livigni, S., Mistraletti, G., \& Petrini, F. (2020). Clinical ethics recommendations for the allocation of intensive care treatments in exceptional, resource-limited circumstances. Retrieved form http://www.siaarti.it/SiteAssets/News/COVID19\%20-\%20documenti\%20SIAARTI/SIAARTI\%20-\%20Covid-19\%20\%20Clinical\%20Ethics\%20Reccomendations.pdf

World Health Organization. (n.d.). Ageism. Retrieved August 31, 2020, from https://www.who.int/ageing/ageism/en/

\section{About the Authors}

Dr. Roger Andre Søraa is a researcher at the Department of Interdisciplinary Studies of Culture (KULT) and Department for Neuromedicine and Movement Science at NTNU Norwegian University of Science and Technology. His main research interests are the digitalization and robotization of society, and the ethical, gendered and epistemological consequences of this. Dr. Søraa is the deputy leader of the Immersive Technology and Social Robotics Laboratory (ImRo-Lab) at NTNU, which does research on welfare technology/gerontechnology. He also leads a research group on the Digitalization and robotization of society at NTNU KULT.

Federico Manzi, PhD, is post-doctoral research fellow at Università Cattolica Sacro Cuore (UCSC) in Milan, Department of Psychology. He obtained a double PhD: in Sciences of the Person and Education from Università Cattolica Sacro Cuore in Milan, Italy, and in Psychology from University of Neuchâtel, Switzerland. He is a member of the Research Unit on Theory of Mind and of the Human-Robot Laboratory at UCSC. He is Member of the Emerging Career Scholar Committee and Early Career Scholar Member of the Publications Committee of the International Society for the Study of Behavioural Development (ISSBD). His main research interest is in developmental psychology, particularly focusing on social cognition and decision-making processes in the human-human and human-robot interaction in a life-span perspective. 
Mark W. Kharas is the Administrative Coordinator of the Immersive Technology and Social Robotics Laboratory (ImRo-Lab) at NTNU and of the LIFEBOTS Exchange and AUTOWORK research projects. He graduated in Religious Studies from Swarthmore College (United States) and obtained a Masters in Theological Study from Harvard Divinity School. His research interests are ethics, religion and spirituality of robotics and new technology.

Antonella Marchetti is Full Professor of Developmental Psychology and Educational Psychology at the Università Cattolica del Sacro Cuore in Milan (Italy), Head of the Department of Psychology, Director of the Research Unit on Theory of Mind, Coordinator of the PhD Programme in Sciences of the Person and Education, Vice-President of the Italian Association of Psychology, ISSBD Executive Committee member and ISSBD Regional Coordinator for Italy, member of the scientific Committee of FEDUF (Foundation for the Financial Education and Saving). Her research interests are in: Theory of Mind development from infancy to older adults, decision-making, Theory of Mind in HRI. Marchetti graduated in Philosophy at the University of Genoa and took her specialization in Psychology at UCM, she also obtained her PhD in Psychology from the University of Pavia. Marchetti published more than 270 scientific contributes, consisting in papers, book chapters, books and edited books. She took part to numerous international and national conferences.

Davide Massaro is Full Professor of Developmental Psychology and Educational Psychology at the Università Cattolica del Sacro Cuore in Milan (Italy), senior member of the Research Unit on Theory of Mind and Didactic Coordinator of the $\mathrm{PhD}$ Programme in Sciences of the Person and Education. Massaro graduated in Psychology and obtained his PhD in Developmental and Social Psychology at Università Cattolica del Sacro Cuore in Milan; he was a visiting researcher for one year at the University of Virginia during his PhD course. His main research areas include Theory of Mind development, decision-making, cognitive biases, Theory of Mind in HRI.

Giuseppe Riva is currently a Full Professor of general psychology with the Universita Cattolica del Sacre Cuore and also the Director of the Applied Technology for Neuro-Psychology Laboratory, Istituto Auxologico Italiano. He is a member of the American Psychological Association. He is actually an Editor in Chief for the Emerging Communication book series and European Editor of the CyberPsychology, Behavior \& Social Networking scientific journal.

J. Artur Serrano, PhD, is a Professor in Care and Assistive Technologies at the Faculty of Medicine and Health Sciences, Norwegian University of Science and Technology (NTNU) in Trondheim. His main research interests are on new approaches to dementia treatment based on immersive technologies, social robots for care, emotional computing and the general area of User eXperience. Has been the Principal Investigator for more than ten research projects including seven EU-funded projects. He is the leader of the Immersive Technology and Social Robotics Laboratory (ImRo-Lab) at NTNU.

PsychOpen GOLD is a publishing service by Leibniz Institute for Psychology (ZPID), Trier, Germany. www.leibniz-psychology.org 